\title{
Change We Can Believe In? Using Political Science to Predict Policy Change in the Obama Presidency
}

Jonathan Woon, University of Pittsburgh

ABSTRACT Based on the results of the 2008 presidential and congressional elections, an analysis using theories and methods of modern political science (pivotal politics theory, ideal point estimates, and bootstrap simulations) suggests that the conditions are ripe for real policy change. Specifically, we should expect policies to move significantly in a liberal direction, few or no policies should move in a conservative direction, and many of the outcomes will be moderate or somewhat to the left of center (rather than far left). Furthermore, the predictions depend as much on partisan polarization and the results of the congressional election as they do on the outcome of presidential election itself.

"We can choose hope over fear, unity over division, the promise of change over the power of the status quo."

-Barack Obama, Canton, Ohio, October 27, 2008

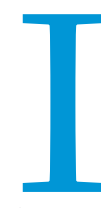

$\mathrm{t}$ is unfortunately all too common for presidents to fail to deliver on their campaign promises, ultimately disappointing both supporters and the general public alikeoccasionally to the point of electoral retribution. George H.W. Bush couldn't deliver on his promise to hold the line on taxes even though he pledged: "read my lips: no new taxes." He was replaced by Bill Clinton, whose first term was marked by a visible failure to reform health care. Eight years after George W. Bush derided "nation building" in a presidential debate, we have the quagmire that is Iraq. Upon re-election, Bush also claimed to have earned "political capital" that he intended to spend reforming Social Security, but his proposals went nowhere fast.

Why should we think that the election of Barack Obama, as historic as it is, should be any different? President Obama inherits a number of substantial policy challenges, including a financial and economic crisis, a hugely unpopular war, popular demand for health care reform, and the ongoing need to protect the country against terrorism. Expectations are so high that any failure to deliver on his promises could be especially devastating to his own

Jonathan Woon is assistant professor of political science at the University of Pittsburgh. His Ph.D. is from Stanford University's Graduate School of Business, and his research interests include congressional policymaking, political parties, and formal theory. He can be reached at woon@ pitt.edu. future electoral prospects, the reputation of the Democratic Party, and to the realization of long-term policy change.

An analysis based on the theories and methods of modern political science suggests that the conditions are ripe for real policy change, that we should expect policies to move significantly in a liberal direction, and that many of the outcomes will be moderate or somewhat to the left of center (rather than far left). The optimism of Obama's supporters is therefore not simply the wishful thinking that it otherwise would be after a typical election. Ironically, such optimistic expectations are realistic precisely because of the cold, hard reality of a policymaking process characterized by "politics as usual." Moreover, the results of the analysis depend as much on the results of congressional elections-especially Senate elections-as they do on the outcome of the presidential contest because neither electoral outcome would have been individually sufficient to produce a significant change.

\section{PIVOTAL POLITICS THEORY, IDEAL POINT ESTIMATES, AND BOOTSTRAPPING}

In order to make systematic predictions about the future, we need a theory of how the political world works and data about the relevant conditions. The theory that we will use here is known as the "pivotal politics" theory, developed by Keith Krehbiel (1998) and David Brady and Craig Volden (1997). The central premise of the theory is that the American legislative process is intentionally designed to make changes in policy difficult. In other words, a strong bias is built into American democratic institutions that 
purposefully favors the power of the status quo and stacks the deck against the promise of change. More specifically, the key components of the theory are that (1) policies and policymakers can be thought of as occupying positions on a single ideological spectrum from liberal to conservative, (2) policy outcomes gravitate toward the favorite policy of the most centrist legislator (i.e., the median legislator, so centrist here is relative rather than absolute), but (3) the extent of such policy change is constrained by constitutional and congressional rules (in particular, the presidential veto, the two-thirds requirement for veto overrides, and the three-fifths cloture requirement for overcoming senatorial filibusters). ${ }^{1}$

For our purposes, the most relevant prediction of the pivotal politics theory concerns a concept known as the gridlock interval. ${ }^{2}$ This interval can be loosely thought of as the set of status quo policies on the ideological spectrum for which policy change is impossible because any such changes toward the middle (the median legislator's position) would either be vetoed or wouldn't have enough votes for a successful veto override or to overcome a potential filibuster. For a liberal president, the endpoints of the interval consist of a veto pivot on the left and a filibuster pivot on the right. In this case, the veto pivot represents the legislator whose vote (along with the votes of all the legislators with positions to the right) are sufficient to override a veto of a policy change from left to right. Similarly, the filibuster pivot in this case is the senator whose vote (along with the votes of all of the legislators with positions to the left) is sufficient to prevent a filibuster of a change in policy from right to left. For a conservative president, the filibuster pivot is on the left and the veto pivot is on the right.

The empirical basis for forming my prediction about the gridlock interval for the new Congress (the 111th) begins with the Common Space version of Poole and Rosenthal's DW-NOMINATE scores (Carroll et al. 2008), which are estimates of the ideological positions or "ideal points" of legislators that result from the statistical analysis of roll-call votes. ${ }^{3}$ To estimate the gridlock interval, I first took all of the ideological scores from returning incumbents and carried them over to the 111th. I then used bootstrap simulations to account for each new member by randomly selecting (with replacement) an ideological position from the members in the 11oth Congress who share the same party affiliation as the new member. ${ }^{4}$ The assumption that new members' ideal points are drawn from the distribution of ideal points in their party is consistent with research arguing that there are essentially two pools of candidates, one for each party (Ansolabehere, Snyder, and Stewart 2001; Woon and Pope 2008). After simulating each new member's position, I then found the positions of the relevant pivots. 5 I repeated this process 2,500 times and averaged the results. I also used the Common Space scores to compute historical gridlock intervals.

\section{PREDICTIONS}

The upper horizontal bar in Figure 1 shows the gridlock interval for the last two years of Bush's presidency (the 11oth Congress). The theory says that over the course of the last two years, the ideological character of policies should have ended up somewhere within this range (numerically, between -0.24 and 0.36 on the Common Space scale). The existing interval therefore represents the range of possible status quo policies. The lower bar shows what my analysis predicts the gridlock interval will be during the beginning of Obama's presidency (its range is between -0.35 and o.07). The positions of President Bush, President Obama (based

\section{Figure 1}

Predicted effect of the 2008 election on the gridlock interval and policy outcomes

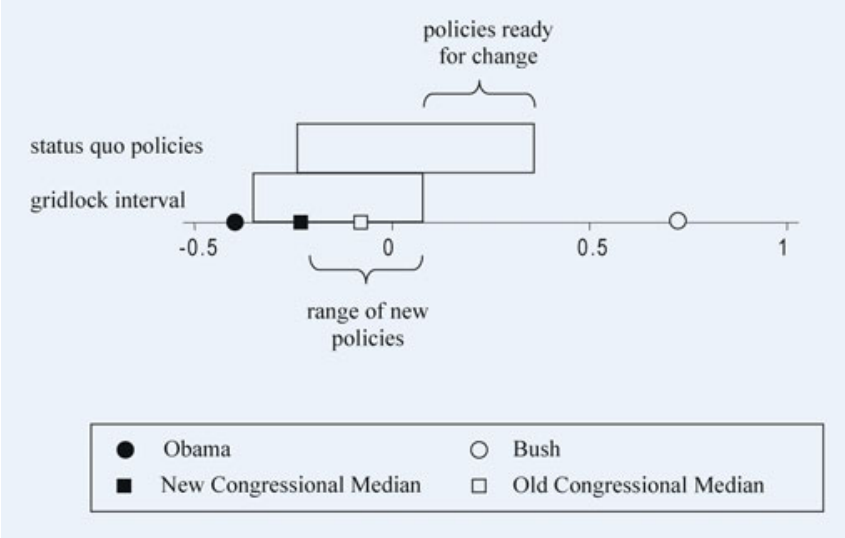

on his Senate record), and the average chamber medians are also displayed on the graph for reference purposes. ${ }^{6}$

What does this graph say about the potential for policy change? The portion of the upper bar that does not overlap with the lower one (from 0.07 to 0.36 ) represents policies that are ripe for change. That is, these policies are "freed up" by the ideological shifts ushered in by the election. According to the analysis, the policies that are ready to change are moderate to conservative ones (corresponding to the positions between a moderate Republican senator, Susan Collins, and a more typical Republican senator, Lamar Alexander). Because the policies that were freed up will be replaced by policies to their left and toward the new median legislators (the average position marked by the solid square), new policies will be decidedly more liberal than the ones they replace. In contrast, in the portion of the spectrum where the upper and lower lines overlap (between -0.24 and 0.07) are policies for which the power of the status quo will prevail. Since these are mostly moderate and liberal policies, we will most likely not observe any policy shifts in a conservative direction (from left to right). Although these predictions may not seem all that surprising to many Obama supporters, history suggests that the optimism of an electoral victory is very often followed by the disappointing reality of gridlock and politics as usual, especially if expectations lack an appropriate theoretical foundation. But, as I describe below, viewed through the analytical lens of pivotal politics theory, the 2008 election was in many ways atypical. Thus, unlike after many previous elections, this time the winning side's expectations about policy change can be grounded in a scientific theory of politics.

But the theory also cautions against expectations of wholesale policy change and, despite the president's rhetoric, against expectations of widespread bipartisanship. Recall that an important aspect of the theory is that constitutional and congressional rules typically serve to constrain policymaking. For the new Congress, this means that leftward changes in policy under a liberal president will have to be filibuster-proof. In other words, new policies cannot be objectionable to the Senate's filibuster pivot. Although it is impossible to identify exactly who the filibuster pivot is, it is most likely one of the three most moderate Republican senators (Arlen Specter, Susan Collins, or Olympia Snowe). This does not necessarily mean that these senators will see their ideal policies 
Table 1

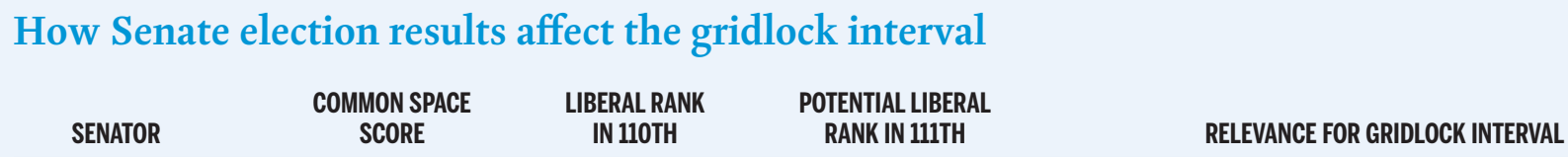

\begin{tabular}{lcccc}
\hline Ben Nelson (D-NE) & -0.015 & 51 & $58-59$ & Filibuster pivot had Democrats won control of 60 seats \\
\hline Specter (R-PA) & 0.047 & 52 & $59-60$ & Potential new filibuster pivot \\
\hline Snowe (R-ME) & 0.093 & 53 & $54-61$ & Potential new filibuster pivot \\
\hline Collins (R-ME) & 0.112 & 55 & $61-62$ & \\
\hline Coleman (R-MN) & 0.194 & 56 & $62^{*}$ & \\
\hline Smith (R-OR) & 0.203 & 57 & a & \\
\hline Stevens (R-AK) & 0.221 & 58 & 63 & Filibuster pivot had no seats changed parties \\
\hline Murkowski (R-AK) & 0.259 & 59 & b & \\
\hline Domenici (R-NM) & 0.265 & 60 & 64 & \\
\hline Warner (R-VA) & 0.274 & 61 & 65 & Veto pivot had McCain won \\
\hline Cochran (R-MS) & 0.289 & 62 & 66 & \\
\hline Voinovich (R-OH) & 0.304 & 63 & 67 & Previous veto pivot \\
\hline Grassley (R-IA) & 0.320 & 64 & 68 & 69 \\
\hline Lugar (R-IN) & 0.324 & 65 & 66 & 70 \\
\hline Bond (R-MO) & 0.329 & 67 & &
\end{tabular}

*Election outcome still undetermined

aDefeated by Democratic challenger

bIncumbent retired, open seat won by Democrat

enacted, but they must view new policies as no less favorable than the policies that are replaced. Furthermore, when the filibusterconstraint binds, the spatial voting model upon which pivotal politics is based also implies that senators who are more conservative than the filibuster pivot-that is, most Republican senators-will prefer the status quo and vote against policy change. Thus, although new policies will pass, they will not necessarily pass by overwhelming bipartisan majorities. Instead, they are more likely to pass with a solid Democratic majority plus just enough Republican votes to prevent a filibuster.

The potential for a filibuster in the Senate therefore limits the range of possible policy outcomes to the right-most portion of the new gridlock interval (from -0.22 to 0.07), as indicated in Figure 1. More concretely, the largest possible policy change will be to take a status quo policy at the right end of the old gridlock interval (near Lamar Alexander's position or the old median Senate Republican) and to move it to a policy near the ideal point of a moderate Democrat (e.g., senator Evan Bayh or the new congressional median). Thus, even though we should observe significant leftward shifts in policy, most outcomes will nevertheless be moderate to left of center.

\section{THE JOINT IMPORTANCE OF PRESIDENTIAL AND SENATE ELECTION OUTCOMES}

The importance of the filibuster pivot in the analysis above suggests that political observers should focus attention on the legislative action that occurs in the Senate. Indeed, when it became clear that Obama would win the presidency, election night commentary quickly turned to whether Democrats would capture the 6o seats needed to invoke cloture on a party-line vote. In this section, I show that even though the Democrats did not reach this magic number, the expansion of the Democratic Senate majority from 51 to (at least) 58 seats nevertheless plays a significant role in shifting the predicted gridlock interval to the left. ${ }^{7}$ Senate elections alone, however, are insufficient to cause this shift. Rather, the major shift in the gridlock interval results from the joint effect of Obama's presidential victory and the Democrats' Senate gains.

Table 1 compares the rank order of senators in the 11oth Senate with their potential ranks in the 111th Senate (where a rank of 1 is most liberal and 100 is most conservative). ${ }^{8}$ In the 11oth Congress, Bob Bennett was the 67th senator from the left, making him the previous veto pivot and the right end of the old gridlock interval. Assuming that new Democratic senators are well to the left of the Republicans they replace (which is consistent with the bootstrap simulations used to predict gridlock interval), the new filibuster pivot in the 111th Senate is likely to be either Arlen Specter or Olympia Snowe (or possibly Susan Collins), who becomes the right end of the new gridlock interval. As a result, the right end of the gridlock interval moves from 0.34 to somewhere between 0.05 and 0.09 .

We can see how this shift is jointly caused by presidential and Senate election outcomes by considering two counterfactual scenarios. First, had Obama won the presidency but the Democrats not picked up any additional seats, the right end of the gridlock interval would have shifted from the old veto pivot to the old filibuster pivot (which would have been John Warner had he not retired). Thus, in an Obama administration with a smaller Democratic Senate majority, the right end of the new gridlock interval 
(0.27) would have been to the right of the pre-Clinton gridlock interval (o.19), and we would therefore have expected much less policy change to occur.

Second, if Democrats picked up the additional Senate seats but McCain had won the presidency, the right end of the gridlock interval in the Senate would shift from the old veto pivot to a new veto pivot that is just barely to its left, from Bob Bennett at 0.34 to Richard Lugar at 0.32. This shift is very small because several new Democratic senators replaced moderately conservative Republicans who were already to the left of the old veto pivot (Gordon Smith, Ted Stevens, Pete Domenici, and John Warner) and whose replacements do not change the location of the veto pivot (but do change the location of the filibuster pivot). When these counterfactuals are considered together, neither the Democrats' Senate gains nor Obama's presidential victory would have been individually sufficient to cause a major shift in the gridlock interval. Instead, the potential for significant policy change is the result of Democratic victories at both the presidential and congressional levels.

Another counterfactual is worth considering: what if Democrats had managed to control the magic number of 60 seats? Would it have been as significant as many pundits claimed? From Table 1 , we can see that if Democrats controlled 6o seats, Ben Nelson (the Democrat to the right of all other Democrats) would become the new filibuster pivot. The right end of the gridlock interval would have shifted even further to the left, to -0.02, so gaining an additional Senate seat or two would have indeed given Democrats a greater advantage. But the pivotal politics framework also suggests that there is nothing particularly special about the number 60 as far as overcoming gridlock is concerned. That is, the difference between Democrats controlling 59 versus 60 votes would account for a difference of about 0.07 in the gridlock interval on the Common Space scale, which is not much more than the 0.04 difference accounted for by moving from 58 to 59 seats. Moreover, Table 1 makes apparent that the lack of a political center means that every additional senator beyond a simple majority critically affects the location of pivotal actors. All of the analysis therefore suggests that Democrats are poised to make significant policy changes despite being a couple of votes shy of a partisan filibusterproof majority.

\section{HISTORICAL COMPARISONS}

How can we put the magnitude of predicted policy changes in historical perspective? Figure $\mathbf{2}$ shows the gridlock interval for every Congress since the last two years of the first President Bush's administration (the 102nd Congress in 1991-1992). Near the top of the graph, we see that President Clinton's election in 1992 freed up some policies to move in a liberal direction, but not to the extent we expect to happen over the next two years. Although Clinton came to office with similarly sized Democratic majorities in both the House and Senate, the interval freed up by the 2008 election is about twice as large as the one freed up in 1992. There are two main reasons for this difference. One is that the increased polarization between parties means that Republicans in Congress have been much more conservative in recent years than they were prior to 1992 (the right end of the interval was 0.19 prior to the 1992 election compared to 0.36 prior to the 2008 election). The other is that Democrats picked up more Senate seats in 2008 than they did in 1992.

Figure 2 also helps to explain why there hasn't been much significant policy change since the Republicans took control of both chambers of Congress after the 1994 midterm election. The

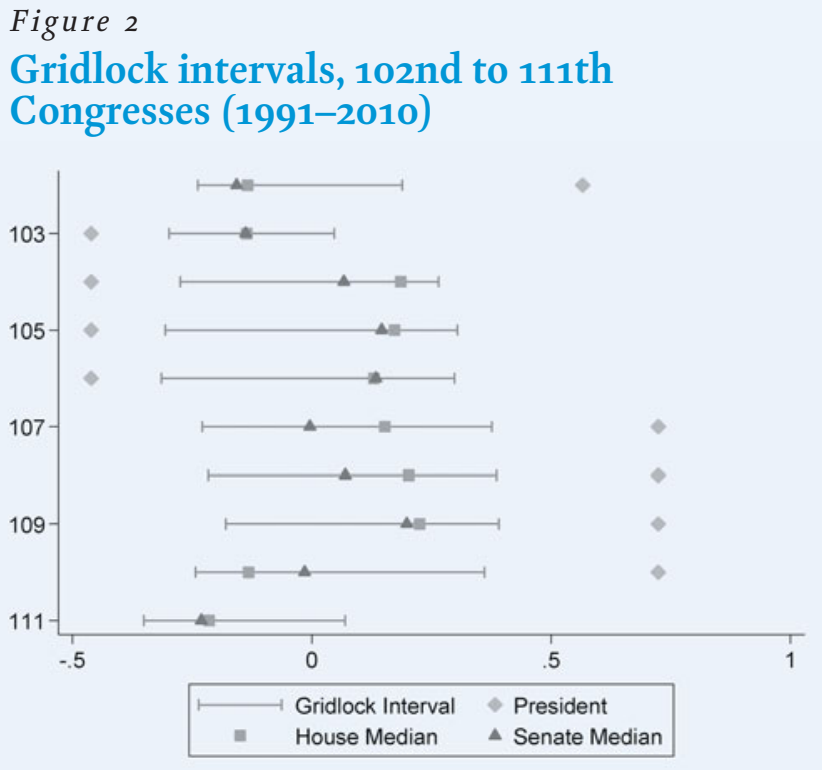

size of the gridlock interval freed up by an election is roughly correlated with the degree of expected policy change, and the figure shows that the status quo points freed up by most elections between 1994 and 2006 have been rather small. For example, the 1994 election resulted in an expansion of the gridlock interval to the right while freeing up a tiny sliver of status quo points on the left. Between 1995 and 2008, the interval did not shift much at all, even when Bush won the presidency in 2000 and when the Democrats regained full control of Congress in the 2006 midterm. It is therefore not surprising that gridlock has been the norm over the last 14 years. In contrast, the length of the gridlock interval freed up in 2008 is approximately seven times the average length of the interval freed up in this period.

In terms of the larger historical context, a comparison to FDR's election in 1932 and Reagan's defeat of Carter in 1980 is shown in Figure 3. Surprisingly, the size of the gridlock interval freed up by the 2008 election is more than twice the size of the space freed up by the 1932 election (when overcoming a filibuster required a more stringent two-thirds rather than three-fifths vote). The gridlock interval continued to shift to the left, however, after the 1934, 1936, and 1938 elections, freeing up a total amount of gridlocked policies that was about $70 \%$ larger than the interval freed up in 2008. Although the comparison to 1932 is very interesting, it should be viewed very cautiously, given the drastic changes in policy that have taken place since then. In 1932, the status quo was a world without Social Security, Medicare, OSHA, the EPA, with few civil liberties, and not least of all, one where society was racially segregated and the election of a black man to the presidency was simply unthinkable. The conservative status quo policies freed up in 1932 were therefore much different from the ones freed up in 2008, even if they occupy similar positions on the Common Space numerical scales.

The comparison between the 2008 and 1980 elections is less likely to suffer from the same inter-temporal comparability problem. Reagan's election precipitated a rightward shift in policy with an emphasis on tax cuts and deregulation, which is seen clearly in Figure 3 by the rightward shift in the gridlock interval (which freed up points on the left). The magnitude of the predicted leftward shift in the next Congress is about $40 \%$ larger than the 
Figure 3

\section{Comparison of predicted 2008 change in gridlock interval with 1932 and 1980 elections}

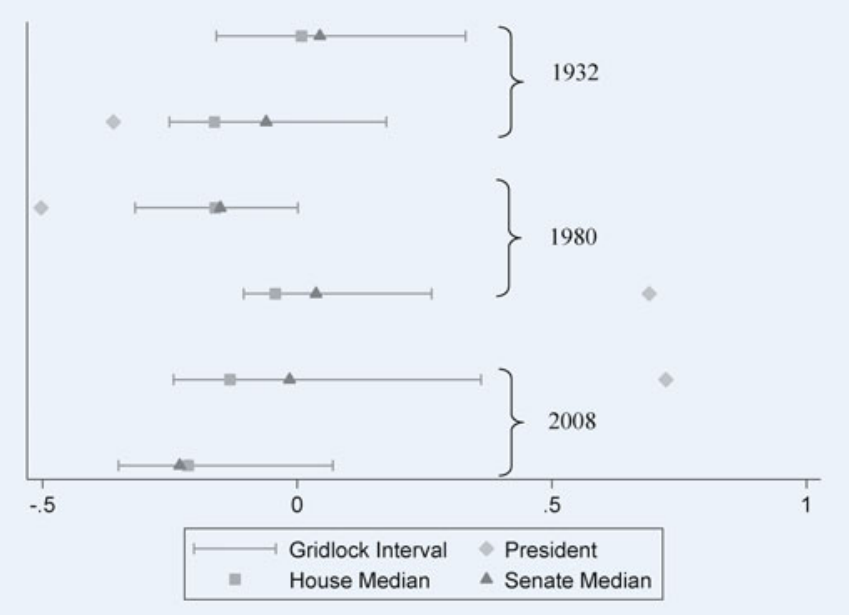

rightward shift that accompanied Reagan's election. Even though the Senate filibuster will constrain the extent of leftward policy movement, the analysis also suggests that some of the most conservative status quo policies may even move to the left of the pre1980 chamber medians. Of course, this should not be interpreted to mean that the next Congress will be rushing to enact the same policies it would have in the late 1970 s, but that it may be end up being similar in ideological character (i.e., degree of government regulation, balance between efficiency and equity, etc). From a policy perspective, the so-called Reagan Revolution may be over.

\section{CONCLUSION}

By the time the 111th Congress comes to an end, we will know with much more certainty whether or not this article's predictions are borne out. If the theory and analysis are correct, then we will observe major policy changes (perhaps even before this article goes to print), but it is also possible that we may not. We might, for example, observe extensive gridlock or policies move in a conservative direction. Theories such as pivotal politics are scientific not simply because they provide systematic explanations, but because they offer bold, falsifiable predictions that can be tested against reality. If it turns out that the power of the status quo prevails, then President Obama's supporters-including many political scientists-will be severely disappointed. But many disappointed political scientists will also have an exciting opportunity for making scientific progress by revising and reassessing the theory and methods used here.

President Obama's supporters have every reason to be excited and optimistic about the future that his historic election promises the nation. Many of them will want to see a dramatic leftward shift in policy; others will want new policies that are mostly moderate and bipartisan. There is also no doubt that partisan and ideological opponents (who would surely be disappointed by this analysis) will seek to stymie and undermine his efforts to enact any policy change at all-that is simply the nature of the political process. Nevertheless, modern political science's analytical theory and methods provide us with a scientific basis for confidently pre- dicting that the promise of change will become reality. However, the change may be entirely in the substance of policy rather than the style of policymaking. Even if the tone in Washington remains shrill and partisan, we can expect to observe a significant leftward shift in policies and therefore a clear break from the policymaking of the previous 14 years.

\section{NOTES}

1. See chapter 2 of Krehbiel (1998) for more detailed but still informal explanation.

2. Alternative theories of lawmaking also make predictions about gridlock intervals, but begin from different premises about the central features of the legislative process. For example, applying Cox and McCubbins's (2005) cartel agenda model of party government would yield significantly different predictions about policy change than those described below. Their theory implies that major changes occur when party control of the House changes.

3. The data can be obtained from Keith Poole's Web site, www.voteview.com. I use the first, or primary, dimension of the scores, which pertains mainly to interparty conflict and preferences about the government's role in the economy (Poole and Rosenthal 1997).

4. A similar bootstrap procedure is used by Adler (2000) and Groseclose (1994) to estimate the distributions of congressional committee characteristics. As of this writing, the close Senate race in Minnesota has not yet been certified, and in my simulations I assume that there is a $50 \%$ probability that the Democrat (Franken) is the eventual winner and a $50 \%$ probability that it is the Republican (Coleman). For new senators with experience in the House, I use their House scores rather than assuming that their ideal point is randomly drawn from their party. Obama and Biden were replaced by new Democratic senators.

5. To account for the possibility that the veto pivots may differ between the two chambers of Congress, I compute the overall gridlock interval using the appropriate Senate filibuster pivot and the most extreme (leftmost) veto pivot.

6. Although Obama's position as president may differ from his position as a senator, previous presidents' positions (estimated in the Common Space scale from data on public position taking) are always more extreme than the relevant veto pivot. If, as president, Obama adopts a position that is more centrist than his Senate record and more centrist than the veto pivot, then his ideal point would become the left end of the new gridlock interval. However, this would not change my predictions or the substantive conclusions of my analysis.

7. Even though Joseph Lieberman (CT) and Bernard Sanders (VT) are independents, they are included in the Democratic seat count because they caucus with the Democrats.

8. For expositional clarity, the discussion of Table 1 ignores the location of the House veto pivot. Careful readers will also notice minor differences in the spatial positions of the relevant pivots between the discussion of Table 1 and the previous section. The difference is that Table 1 ignores the uncertainty incorporated into the bootstrapped estimates.

\section{REF E R E N C ES}

Adler, E. Scott. 200o. "Constituency Characteristics and the 'Guardian' Model of Appropriations Subcommittees, 1959-1998.” American Journal of Political Science 44 (1): 101-14

Ansolabehere, Stephen, James M. Snyder, Jr., and Charles Stewart III. 2001. "Candidate Positioning in U.S. House Elections." American Journal of Political Science 45 (1): 136-59.

Brady, David W., and Craig Volden. 1997. Revolving Gridlock: Politics and Policy from Carter to Clinton. Boulder, CO: Westview Press.

Carroll, Royce, Jeff Lewis, James Lo, Nolan McCarty, Keith Poole, and Howard Rosenthal. 2008. "Common Space DW-NOMINATE Scores with Bootstrapped Standard Errors (Joint House and Senate Scaling)." http://voteview.com/ dwnomin_joint_house_and_senate.htm.

Cox, Gary W., and Mathew D. McCubbins. 2005. Setting the Agenda: Responsible Party Government in the U.S. House of Representatives. New York: Cambridge University Press.

Groseclose, Tim. 1994. "Testing Committee Composition Hypotheses for the U.S. Congress." Journal of Politics 56 (2): 440-58.

Krehbiel, Keith. 1998. Pivotal Politics: A Theory of U.S. Lawmaking. Chicago: University of Chicago Press.

Poole, Keith T., and Howard Rosenthal. 1997. Congress: A Political-Economic History of Roll Call Voting. New York: Oxford University Press.

Woon, Jonathan, and Jeremy Pope. 2008. "Made in Congress? Testing the Electoral Implications of Party Ideological Brand Names." Journal of Politics 70 (3): $823-36$ 